\title{
RETURNS AND RISK ON BITCOIN: A VOLATILITY MEASUREMENT BY UNIT ROOT TEST
}

DOI: 10.17261/Pressacademia.2019.1161

RJBM- V.6-ISS.4-2019(8)-p.315-319

\section{Ibrahim Mert}

Istanbul Aydin University, Anadolu Bil Vocational School, Business Management, Istanbul, Turkey ibrahimm@aydin.edu.tr, ORCID: 0000-0003-3745-8405

Date Received: October 10,2019

Date Accepted: December 21, 2019

To cite this document

Ibrahim, M., (2019). Returns and risk on Bitcoin: a volatility measurement by unit root test. Research Journal of Business and Management (RJBM), V.6(4), p.315-319

Permemant link to this document: http://doi.org/10.17261/Pressacademia.2019.1161

Copyright: Published by PressAcademia and limited licenced re-use rights only

\section{ABSTRACT}

Purpose - The major reason of performing this study is to examine volatility of the Bitcoin prices. As known, Bitcoin became more popular when its price movements changed radically. It has been increasing for years since the date of first issuance in 2010 and reached highest level in its history by testing 19,345 USD. Based on this price movement, risk and returns are taken together for making investment in Bitcoin since huge decreasing observed in respond to the these increases.

Methodology - In this study, Bitcoin prices are analyzed monthly basis through the time series analysis. Data related to closing prices of Bitcoin are obtained from investing.com web site. We established analysis based on sample consist of Bitcoin prices for the period between 2016 and 2019. Augmented Dickey Fuller (ADF) and Phillips Perron (PP) unit root test is applied to find out whether series are stationary or not.

Findings- According to test results, the series of Bitcoin prices are not stationary yet. Although different fluctuating degree can be seen by years, generally it can be stated that Bitcoin prices are still volatile.

Conclusion- Based on findings, Bitcoin prices may still be considered as volatile instrument. Therefore, investors should be careful when they want to include this investment tool to the portfolio since it represents risky instrument properties.

Keywords: Crypto currencies, Bitcoin, unit root test, time series.

JEL Codes: C00, C32

\section{INTRODUCTION}

Cryptocurrency may be considered one of the greatest inventions of the last century. It is also possible to define the cryptocurrency as a financial revolution, which has many advantages over the classical money concept issued by the governments. Cryptocurrencies are online digital payment tools that replace traditional paper money that is subject to physical circulation. The first example of cryptocurrencies is Bitcoin, which was introduced in 2008 by Satashi Nakamoto. Nakamoto described cryptocurrencies as peer to peer version electronic cash (Nakamoto, 2008: 2).

The origin of the cryptocurrency concept online digital records and these records can be duplicated easily and don't bring costs and therefore it can be used many times in financial transactions (Chiu and Koeppl, 2019: 1). Compared to credit cards with a cash payment system, it will be seen that the cash payment system provides more anonymity (Narayanan et.al, 2016:14). Because once the credit card is issued, the bank will be able to follow the personal expenditures more easily. However, this is not possible with cash payments. Basic characteristics of the Bitcoin can be stated as follows (Lee, 2015:37):

- It is based on system that works on decentralized peer-to-peer network. It means this system cannot be controlled by a single person, group or even government.

- It is also completely distributed that ensures every computer can connect to each other.

- The system is global and very fast. Thanks to this feature, it allows financial integration and the speed of the financial transactions are higher.

- It has reliability and secure system features. In this system there is no settlement risk. It is suitable for cost savings. 
In the second part of the study, the previous studies included in the literature about Bitcoin are provided. In part 3, the application of the study is performed and in this section, whether the Bitcoin price series is stationary is measured by unit root tests. In the last part of the study, findings related to test results are analyzed and interpreted.

\section{LITERATURE REVIEW}

Adrian et.al (2015), they carried out an econometric analysis of the presence of bubbles claimed to exist in the Bitcoin market. They examined the short-term bubbles seen during the 2010-2014 period. In the second part of the $2011-2013$ period, 3 large bubbles lasting between 66 and 106 are identified. They reported that the last bubble is the largest and resulted in the collapse of the Mt Gox Index.

Katsiampa (2017), investigated the optimal conditional heteroskedasticity model which is best suited to Bitcoin price data. The best model was found to be the AR-CGARCH model emphasizing the importance of including both a short- and long-term component of conditional variance.

Corbet et. al. (2018), investigated the price bubbles seen in the cryptocurrencies of Bitcoin and Ethereum by using an econometric method. Unlike the previous studies in the literature, the main drivers of price in both currencies have been examined. They produced significant rates in terms of economically and computationally and tried to determine the date of bubbles through these rates. According to the results of the studies, Bitcoin is almost at the bubble stage. Considering that there is no significant difference between the Bitcoin price at the time of the study and the current price level, it can be stated that Bitcoin is still at the bubble level.

Koutmos (2018), examined the empirical relationship between Bitcoin returns and trading activities. As a contribution to the current literature, which reveals that Bitcoin prices may act contrary to basic economic principles, this study investigated whether price movements are related to trading transactions. According to the results of the analysis, it was observed that a standard deviation of one unit in the transactions caused a $30 \%$ increase in returns on the third day following the shock. On the sixth day, however, he found that there was a price movement in the opposite direction and that all earnings were therefore lost. As a result of the bi-directional relationship between return and transaction activities, it was found that the deviation in returns had more effect on transaction activity.

Ozyesil (2019), examined the interactions between Bitcoin and Exchange Rates. He conducted VAR model to find out Bitcoin is becoming an alternative investment tool for the exchange rates. According to the results of analysis, there is no significant relationship between Bitcoin and USD and therefore it is concluded that Bitcoin and Foreign Exchange Rates have not become substitution for each other yet.

Mensi et.al. (2019), investigated the effects of structural breaks on Bitcoin and Ethereum price returns. In their studies, they have determined the structural changes and their long-term effects by using generalized autoregressive conditional heteroscedasticity models such as GARCH, FIGARCH HYGARCH. They also found out that, by considering long memory and switching states the persistence level of both returns and volatility decreases.

Katsiampa et.al. (2019), by using BEKK model with three pairs of variables, they examined conditional volatility dynamics and conditional correlation relationships between Bitcoin-Ether, Bitcoin-Litecoin and Ether-Litecoin pairs of criterion currencies. Although the price volatility of the cryptocurrency is determined to be based on their own past shocks, they also observed bidirectional shock effects between Bitcoin and both Ether and Litecoin and the unidirectional spillovers effect from Ether to Litecoin. In addition, the unidirectional volatility spillover effect is observed between all three cryptocurrencies.

Geuder et.al. (2019), analyzed the bubble behaviors in Bitcoin prices during the period $2016-2018$ by using The Phillips et al. (2015) PSY methodology. According to the results of the analysis, they found that the price bubble behavior was a common and repeated result of Bitcoin prices. In addition to this, they found that after 6 December 2017, the effect of bubble behavior on Bitcoin prices decreased.

\section{DATA AND METHODOLOGY}

With this study, volatility degree of the Bitcoin prices are calculated. Analysis is based on a sample includes Bitcoin prices monthly basis that covers the 10.03.2016-13.12.2019 period.

The data are obtained from the investing.com. In the selection of the analysis period, we tried to determine the broadest time range that fluctuating is beginning. Therefore, period that covers from 10.03.2016 to 13.12 .2019 is chosen. In the final version of the sample, there are 1374 daily data. The data used in the analysis is shown in Graph 1 as follow: 


\section{Graph 1: Bitcoin Returns and Volume}

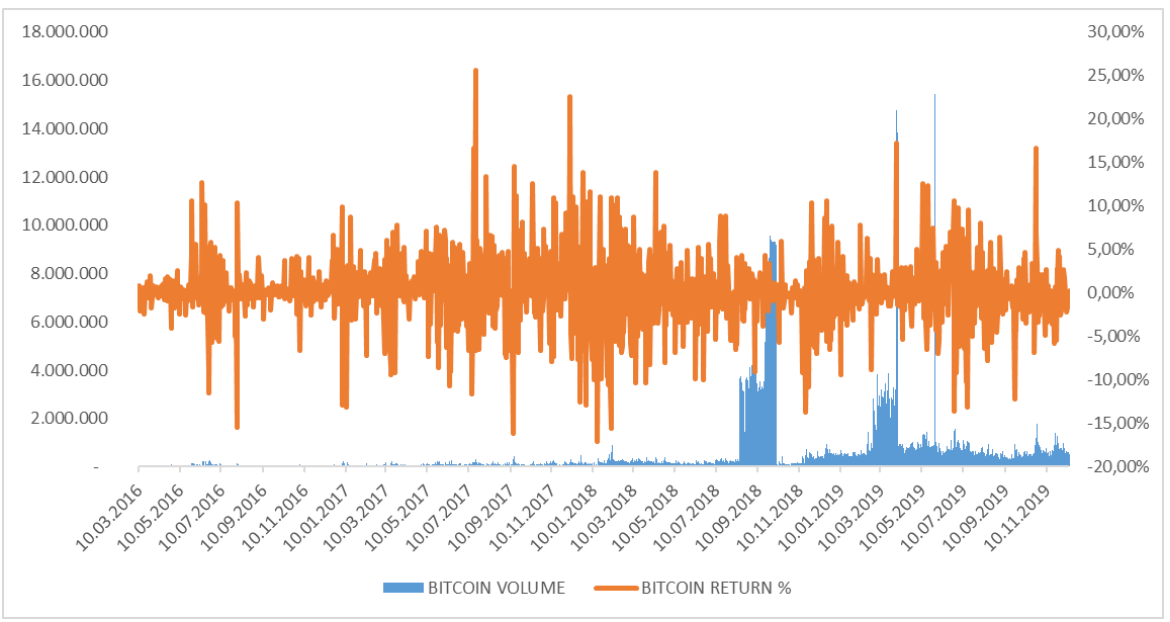

Stationarity of the series are examined by the Augmented Dickey Fuller (ADF) and Phillips Perron (PP) tests. ADF is selected because of being most widely preferred approach for unit root test. In addition, PP is chosen because it considers that series may include trend and therefore it provides more stable results than ADF.

Descriptive Statistics of the Sample are provided in Table.1 as follows:

Table 1: Descriptive Statistics of the Sample

\begin{tabular}{|l|c|}
\hline (10.03.2016-12.12.2019) & BITCOIN \\
\hline Mean & $5.056,77$ \\
\hline Median & $4.335,10$ \\
\hline Maximum & $19.345,50$ \\
\hline Minimum & 408,20 \\
\hline Std. Dev. & $3.905,47$ \\
\hline Skewness & 0,606 \\
\hline Kurtosis & $-0,183$ \\
\hline Jarque-Bera & 86,07 \\
\hline Probability & - \\
\hline Sum & $6.942 .946,40$ \\
\hline Observations & 1373 \\
\hline
\end{tabular}

\section{TEST RESULTS AND DISCUSSIONS}

In order to get robust results, stationary degree of the series should be examined. Stationary level of the series are determined by unit root tests. If the series are stationary, the regression model that will be established on this series will not cause spurious regression problem. Because when a series become stationary, it will move around it average so that outlier numbers (observations) can be eliminated. In this study, unit root test is conducted via the ADF and Phillips (PP) approaches.

Established hypotheses of these tests are shown as follow:

$H_{0}$ : Series are not stationary.

$H_{1}$ : Series are stationary. 
To find out whether the series are stationary or not, probability value of the ADF and PP tests should be taken into consideration. If the probability value is lower than $\% 5$ than it is accepted the series are stationary. If the series are not stationary and becomes stationary after calculating their first differences they are called as I(1).

We performed ADF and PP unit root tests and results are shown as follow:

Table 2. Unit Root Test Results

\begin{tabular}{|l|c|c|c|c|}
\hline \multirow{2}{*}{ Variable } & \multicolumn{2}{|c|}{ Origin Level } & \multicolumn{2}{c|}{ First Difference } \\
\cline { 2 - 5 } & $\begin{array}{l}\text { Probability Value } \\
\text { of the ADF Test }\end{array}$ & $\begin{array}{l}\text { Probability Value } \\
\text { of the PP Test }\end{array}$ & $\begin{array}{l}\text { Probability Value } \\
\text { of the ADF Test }\end{array}$ & $\begin{array}{l}\text { Probability Value } \\
\text { of the PP Test }\end{array}$ \\
\hline LnBIT & 0.65 & 0.57 & $0.001^{*}$ & $0.001^{*}$ \\
\hline
\end{tabular}

Note: The optimum lag length is determined according to Akaike Criterion. Optimum bandwith in the PP test is determined based on NeweyWest Method. * refers to stationarity at $\% 10$ significance level.

According to test results, it can be inferenced that Bitcoin prices for the 10.03.2016-12.12.2019 are not stationary based on probability values. They become stationary once their $1^{\text {st }}$ difference are taken. Therefore, it suitable to define Bitcoin price series as I(1). Following illustration indicated remarkable differences between original level values and first differences.

Figure 1:. Histogram Charts of Original level Values and $1^{\text {st }}$ Differences Values

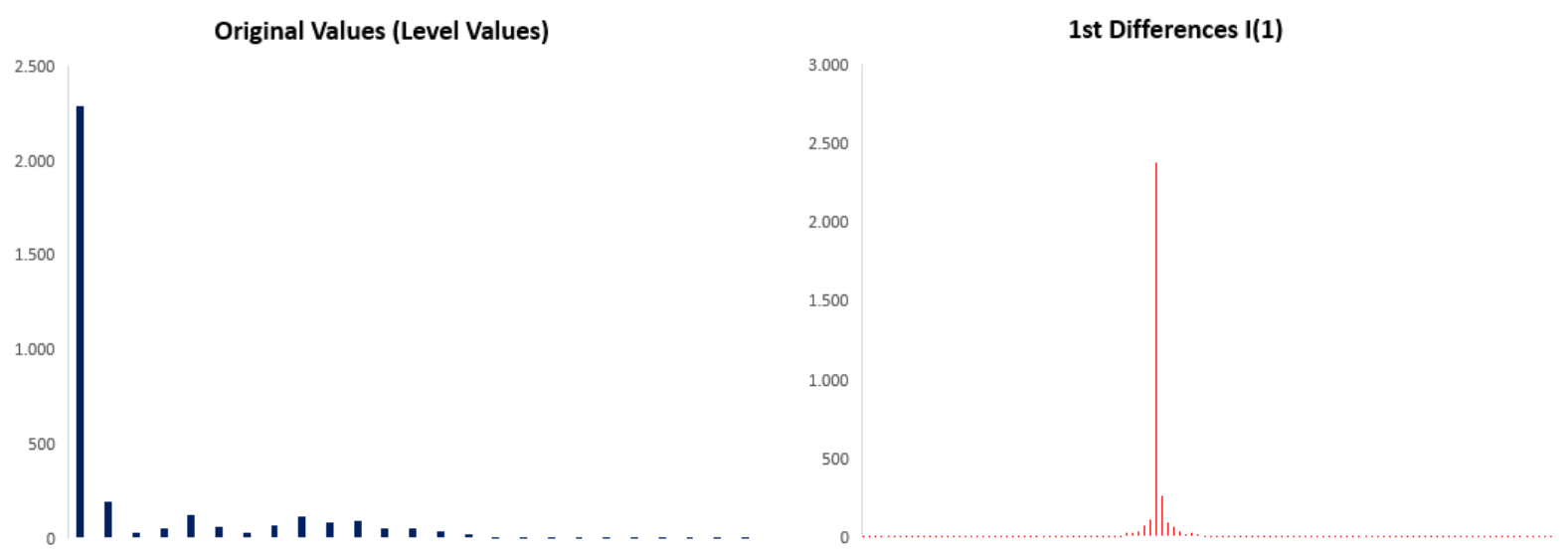

As Figure 1 shows, based on the original level values, Bitcoin does not tend to indicate normal distribution properties while after calculating first differences, it became to represent normal distribution properties.

\section{CONCLUSIONS AND RECOMMENDATIONS}

The concept of cryptocurrency is one of the most popular topics in the financial universe thanks to its radical difference from the traditional money concept and its revolutionary innovations. Especially Bitcoin hat is emerged in 2008, has attracted the attention of many investors due to its price performance. Bitcoin prices have seen historical record levels in the last 10 years and reached an all-time high of $\$ 19,345$ on 16.12.2017. Later on, many cryptocurrencies were issued thanks to the advantages of the cryptocurrency concept and the price performance of Bitcoin. Many countries even went on to issue their own cryptocurrency.

In this study, we discussed whether Bitcoin can still be considered risky as an investment tool. We analyzed whether a time series of Bitcoin prices is stationary. For this purpose, we used ADF and PP unit root tests and interpreted the results. For analysis, we used Excel 2016 and Eviews 9 program.

According to the analysis results, we found that Bitcoin prices are not stable in both unit root tests. We observed that bitcoin prices became stationary only after the first differences are calculated Based on this finding, it is possible to interpret that Bitcoin, as an investment instrument, still follows a volatile course. It will be more beneficial for investors to evaluate Bitcoin with its risk and its returns together to generate higher capital gains. Since it is possible to get stationarity in Bitcoin prices after calculating $1^{\text {st }}$ differences, investors certainly should pay attention volatility of Bitcoin prices in order not to face with spurious regression problem. Because series are based on first differences do not represent original values that's why it may 
provide misleading information for the investors. Particularly, when needed to establish regression analysis, cointegration analysis should be performed to find out relationship of Bitcoin prices with another variable.

\section{REFERENCES}

Adrian (Wai-Kong) Cheung, Eduardo Roca \& Jen-Je Su (2015) Cryptocurrency bubbles: an application of the Phillips-Shi-Yu (2013) methodology on Mt. Gox bitcoin prices, Applied Economics, 47:23, 2348-2358

Chiu, J., Koeppl, T.V. (2019). The Economics of Cryptocurrencies - Bitcoin and Beyond, Bank of Canada Staff Working Paper, 1-56.

Corbet, S., Lucey, B., Yarovaya, L. (2018). Datestamping the Bitcoin and Ethereum Bubbles, Finance Research Letters, 26, 81-88.

Dickey, D. and W. Fuller (1979). “Distribution of the Estimators for Autoregressive Time Series with a Unit Root," Journal of the American Statistical Association, 74, 427-431.

Dickey, D. and W. Fuller (1981). “Likelihood Ratio Statistics for Autoregressive Time Series with a Unit Root,” Econometrica, 49, 1057-1072.

Geuder, J., Kinateder,H., Wagner, N.F. (2019). Cryptocurrencies as Financial Bubbles: The case of Bitcoin, Finance Research Letters, 31,179 184.

Göçer, İ. (2016). Lisans ve lisansüstü için ekonometri. 1. Baskı. İzmir: Lider Yayınları.

Katsiampa, P. (2017). Volatility Estimation for Bitcoin: A Comparison of GARCH Models, Economic Letters, 158, 3-6.

Katsiampa, P., Corbet, S., Lucey, B. (2019). Volatility spillover effects in leading cryptocurrencies: A BEKK-MGARCH analysis Finance Research Letters, 29, 68-74.

Koutmos, D. (2018). Bitcoin Returns and Transaction Activity, Economic Letters, 167, 81-85.

Lee Kuo Chuen, D. (ed.) Handbook of digital currency, 1st edn, Elsevier (2015)

Nakamoto, S., 2008. Bitcoin: A Peer-to-Peer Electronic Cash System. Bitocin.org.

Narayanan, A., Bonneau, J., Felten, E., Miller, A., Goldfeder, S. (2016). Bitcoin and Cryptocurrencies Technologies, Princeton University Press.

Mensi, W., Al-Yayhee, K.H., Kang, S.H. (2019), Structural breaks and double long memory of cryptocurrency prices: A comparative analysis from Bitcoin and Ethereum, Finance Research Letters, 29, 222-230.

Ozyesil, M. (2019). A research on interaction between Bitcion and foreign exchange rates. Journal of Economics, Finance and Accounting (JEFA), V.6(1), p.55-62.

Perron, P. and S. Ng. (1996). "Useful Modifications to Some Unit Root Tests with Dependent Errors and their Local Asymptotic Properties," Review of Economic Studies, 63, 435-463.

Phillips, P.C.B. and P. Perron (1988). “Testing for Unit Roots in Time Series Regression,” Biometrika, 75, 335-346.

Tarı, R. (2012). Ekonometri. 8. Baskı. Kocaeli: Umuttepe Yayınları.

www.investing.com, (Accessed in 15.12.2019). 